University of Nebraska - Lincoln

DigitalCommons@University of Nebraska - Lincoln

Faculty Publications from the Department of Electrical \& Computer Engineering, Department Electrical and Computer Engineering

4-1990

\title{
Pulsed laser annealing of GaAs implanted with Se and Si
}

\author{
Andrzej Rys \\ Kansas State University \\ Yanan Shieh \\ Kansas State University \\ Alvin Compann \\ Kansas State University \& University of Toledo \\ Huade Yao \\ University of Nebraska- Lincoln \& Kansas State University \\ Ajit Bhat \\ Kansas State University \& University of Toledo
}

Follow this and additional works at: https://digitalcommons.unl.edu/electricalengineeringfacpub

Part of the Computer Engineering Commons, and the Electrical and Computer Engineering Commons

Rys, Andrzej; Shieh, Yanan; Compann, Alvin; Yao, Huade; and Bhat, Ajit, "Pulsed laser annealing of GaAs implanted with Se and Si" (1990). Faculty Publications from the Department of Electrical and Computer Engineering. 592.

https://digitalcommons.unl.edu/electricalengineeringfacpub/592

This Article is brought to you for free and open access by the Electrical \& Computer Engineering, Department of at DigitalCommons@University of Nebraska - Lincoln. It has been accepted for inclusion in Faculty Publications from the Department of Electrical and Computer Engineering by an authorized administrator of DigitalCommons@University of Nebraska - Lincoln. 


\section{Pulsed laser annealing of GaAs implanted with Se and Si}

\author{
Andrzej Rys, MEMBER SPIE \\ Yanan Shieh \\ Kansas State University \\ Department of Electrical \\ and Computer Engineering \\ Durland Hall \\ Manhattan, Kansas 66506
}

\section{Alvin Compaan* \\ Huade Yaot \\ Ajit Bhat*}

Kansas State University

Department of Physics

Cardwell Hall

Manhattan, Kansas 66506

\begin{abstract}
Carrier activation and mobility were studied by Raman spectroscopy and the Hall effect in pulsed laser annealed samples of GaAs implanted with doses of Si and Se from $2.2 \times 10^{12}$ to $6.0 \times 10^{14} \mathrm{~cm}^{-2}$. The samples were annealed using a pulsed $\mathrm{XeCl}$ excimer laser $(\lambda=308 \mathrm{~nm})$ and a pulsed dye laser $(\lambda=728 \mathrm{~nm})$ with energy densities from 0.06 to $0.9 \mathrm{~J} / \mathrm{cm}^{2}$ and pulse durations of about $10 \mathrm{~ns}$. Very high carrier concentrations of $3 \times 10^{19}$ and $1.5 \times 10^{19} \mathrm{~cm}^{-3}$ were obtained for the best $n$-type GaAs samples annealed with the dye and excimer lasers, respectively. The dye laser consistently produced higher activation than excimer laser annealing. A transient reflectivity signal was used to identify the GaAs melt threshold and the melt phase dynamics of the GaAs under the nitride cap. The threshold energies for cap damage were 0.34 and $0.12 \mathrm{~J} / \mathrm{cm}^{2}$ for the excimer and dye lasers, respectively. Raman spectroscopy was used to identify the threshold energies for the GaAs implant layer recrystallization and for optimum carrier activation. Four major peaks were observed on the photoinduced current transient spectra in the temperature range of 60 to $400 \mathrm{~K}$, corresponding to traps with activation energies between 0.06 to $0.80 \mathrm{eV}$.
\end{abstract}

Subject terms: laser annealing; GaAs; ion implantation; transient reflectivity; Hall effect; Raman spectroscopy; deep level transient spectroscopy.

Optical Engineering 29(4), 329-338 (April 1990).

\section{CONTENTS}

1. Introduction

2. Experimental

2.1. Annealing

2.2. Optical tests

2.3. Electrical measurements and a multiple etching technique

2.4. Photoinduced current transient spectroscopy (PITS)

3. Discussion of results

3.1. Optical measurements

3.2. Hall measurements

3.3. Depth profiling of carriers by a multiple etching technique

3.4. Results of PITS experiment

4. Summary

5. Acknowledgments

6. References

\section{INTRODUCTION}

Annealing of ion implantation produced damage in $\mathrm{GaAs}$ in general has been dominated by the need to prevent erosion and maintain surface stoichiometry during the high-temperature process. Arsenic loss and surface decomposition are usually pre-

*Current affiliation: University of Toledo, Dept. of Physics and Astronomy, Toledo, OH 43606.

\footnotetext{
${ }^{\dagger}$ Present address: University of Nebraska, Dept. of Electrical Engineering, Lincoln, NE 68588 .
}

Paper 2722 received April 20, 1989; revised manuscript received Jan. 16, 1990; accepted for publication Jan. 29, 1990. This paper is a revision of Paper 94509, presented at the SPIE conference Advanced Processing of Semiconductor Devices II, March 17-18, 1988, Newport Beach, Calif. The paper presented there appears (unrefereed) in SPIE Proceedings Vol. 945.

(C) 1990 Society of Photo-Optical Instrumentation Engineers. vented during conventional thermal annealing through the use of an encapsulated dielectric layer that is deposited directly on the GaAs surface. While quite successful for low-dose samples, this technique has had a limited success in obtaining high carrier activation of $\mathrm{Si}$ or $\mathrm{Se}$ implanted samples. ${ }^{1}$ The maximum electron concentrations achieved in early n-type implantation experiments were low $^{2}$ due to the fast diffusion of $\mathrm{Ga}$ in a $\mathrm{SiO}_{2}$ encapsulant. $A \mathrm{Si}_{3} \mathrm{~N}_{4}$ cap proved to be much better in that respect. However, $\mathrm{Si}_{3} \mathrm{~N}_{4}$ caps that contain appreciable amounts of oxygen do not act as effective barriers to $\mathrm{Ga}$ diffusion either. It has been indicated, from Raman spectroscopy measurements on the $\mathrm{Si}_{3} \mathrm{~N}_{4}$ or $\mathrm{SiO}_{2}$ encapsulated $\mathrm{GaAs}$, that an interfacial strain is a motive force of the thermal conversion effect of $\mathrm{Cr}$ doped semi-insulating substrates. ${ }^{3}$ This is a very important phenomenon because it can significantly affect the doping profile of the implanted layer. ${ }^{4,5}$ An AlN cap results in less outdiffusion of $\mathrm{Cr}$ because of the similarity in expansion coefficients of AlN and $\mathrm{GaAs}$ but is very difficult to remove with standard etches.

The encapsulation of $\mathrm{GaAs}$ can produce additional complications for rapid annealing with arc lamps and for laser annealing since these techniques are sensitive to the temperature-dependent optical coupling through the capping layer. The various problems associated with dielectric caps mentioned above as well as incomplete adherence, cracks in the layers, and the contamination of $\mathrm{GaAs}$ with impurities trapped in the dielectric or at the surface of the semiconductor prompted our study of pulsed laser annealing techniques, in which the substrate is not heated and thus does not expand to produce differential strain at the interface.

Although it was found that laser annealing could be conducted on a bare GaAs surface without drastic surface deterioration if the laser energy did not significantly exceed the melt threshold, ${ }^{6}$ 
other more critical problems emerged. The attempts to activate low-fluence implants $\left(<10^{14} \mathrm{~cm}^{-2}\right)$ by pulsed beam annealing have been unsuccessful. For low-dose implants the pulsed beam annealing of Si or Se implanted GaAs n-type layers has resulted in low activation of charge carriers, although the crystal regrowth was fairly good. ${ }^{7,8}$ Typical electron mobilities in pulsed annealed GaAs are about one-third those found in bulk GaAs of comparable carrier concentrations. ${ }^{9}$ For samples with heavier implants the carrier mobilities were invariably low ${ }^{10,11}$ despite the exceptionally high doping levels that resulted. A surface concentration as high as $4 \times 10^{19} \mathrm{~cm}^{-3}$ was obtained by pulsed electron beam annealing of Se implanted GaAs. ${ }^{12}$ Pulsed laser annealing of $\mathrm{Si}_{3} \mathrm{~N}_{4}$ capped $\mathrm{GaAs}$ with a ruby laser indicated that a higher concentration results when annealing is done through the cap. ${ }^{13}$ It was pointed out, however, that the higher carrier concentration inferred from electrical measurements may be due to silicon incorporation from the $\mathrm{Si}_{3} \mathrm{~N}_{4}$ cap. Pulsed laser annealing of p-type implanted GaAs generally results in good crystal regrowth as well as good carrier activation. ${ }^{6}$

In view of the above results, which are in some cases highly promising and in others quite disappointing, we chose to do a parallel study with some samples furnace annealed and other identical samples pulsed laser annealed. For the laser annealing we used two very different lasers-one in the deep red and one in the ultraviolet. Both the dye laser at $728 \mathrm{~nm}$ and the excimer laser at $308 \mathrm{~nm}$ have excellent characteristics for use in laser processing. ${ }^{14}$ Both systems have much lower coherence than ruby or Nd:YAG lasers, which serves to diminish the problems of laser speckle. The Nd:YAG pumped dye laser, for example, is a very high gain system with two amplifier stages; consequently, there is little longitudinal mode structure within the $\sim 0.05 \mathrm{~cm}^{-1}$ linewidth. Both lasers have a very short pulse duration $-8 \mathrm{~ns}$ for the dye and $12 \mathrm{~ns}$ for the excimer. Most important, however, the two lasers have very different penetration depths in GaAs. The dye laser is absorbed in about $\mathbf{5 0 0}$ $\mathrm{nm}$, whereas the excimer is absorbed in $13 \mathrm{~nm} .{ }^{15}$

Since pulsed laser annealing in $\mathrm{GaAs}$ is quite new, we proceeded systematically, first with a transient reflectivity study of the threshold and duration of the melt phase as a function of the laser pulse energy, comparing the behavior with and without $\mathrm{Si}_{3} \mathrm{~N}_{4}$ caps. ${ }^{16}$ Second, we performed Raman spectroscopy measurements on a large number of anneal spots. ${ }^{14}$ This nondestructive measurement provides a clear indication of the pulse energy threshold for epitaxial regrowth. The Raman scattering also provides a reasonably good indication of the amount of carrier activation in the samples. Finally, we prepared larger anneal areas that were suitable for applying Hall contacts. These samples were annealed over a narrow range of energies that the Raman scattering indicated might be optimum for the highest carrier activation. The sheet carrier concentration, sheet resistivity, and mobility were measured on these samples. The Hall samples were also tested by photoinduced current transient spectroscopy (PITS) to determine the energy activation, the capture cross section, and a density of deep-level defects. Some results of this experiment are presented in this paper, but the details of deep trap parameters and their correlation with a dose of implanted impurities, carrier concentration, and mobility will be published later.

Very high carrier concentrations of $3 \times 10^{19} \mathrm{~cm}^{-3}$ and $1.5 \times 10^{19} \mathrm{~cm}^{-3}$ were obtained for the best $\mathrm{n}$-type GaAs samples annealed with the dye laser and the excimer laser, respectively.
These results show that good carrier activation can be achieved with a pulsed laser if the annealing is done in a narrow energy window through the cap and at pulse energies well below those used in previous laser annealing studies. ${ }^{14}$ Dye laser annealing consistently produced slightly higher activation than excimer laser annealing.

\section{EXPERIMENTAL}

\subsection{Annealing}

The GaAs substrates with (100) orientation were implanted through the cap at an energy of $140 \mathrm{keV}$ for Si dopants and an energy of $320 \mathrm{keV}$ in the case of Se impurities. The Si and Se doped samples were capped with approximately $60 \mathrm{~nm}$ (the cap thickness for Si doped samples varied from 59 to $63 \mathrm{~nm}$ ) and about $79 \mathrm{~nm}$ of $\mathrm{Si}_{3} \mathrm{~N}_{4}$, respectively. Three different ion doses of $\mathrm{Si}$ were used, $2.0 \times 10^{13}, 6.0 \times 10^{13}$, and $2.0 \times 10^{14} \mathrm{~cm}^{-2}$, and one dose of Se ions of $2.2 \times 10^{12} \mathrm{~cm}^{-2}$. After implantation the substrates were cleaved into smaller samples for subsequent laser annealing. For studies of capless annealing, the silicon nitride cap was etched off in $49 \% \mathrm{HF}$ for $5 \mathrm{~min}$ at room temperature.

The samples were annealed using a pulsed $\mathrm{XeCl}$ excimer laser $(\lambda=308 \mathrm{~nm}$, Questek model 2240) using weak focusing with an aspheric quartz lens and a beam homogenizer. The laser beam was weakly diffused by a ground and etched quartz plate and then focused again with spherical quartz focusing lenses. Two types of apertures were placed $\sim 0.5 \mathrm{~mm}$ in front of the sample during annealing. A circular aperture with a $0.5 \mathrm{~mm}$ diameter was used on samples intended for optical characterization (Raman spectroscopy and transient reflectivity). This allowed us to obtain a large number of annealed spots. A cloverleaf pattern (approximately $2.5 \mathrm{~mm}$ between the corners of adjacent "ears") was used for samples that were later studied by electrical as well as optical methods. The annealing with a Nd:YAG pumped dye laser (Lambda Physik model 2002) at wavelength $\lambda=728 \mathrm{~nm}$ was done without an aperture and without the beam homogenizer. The dye laser produced a smooth profile across beam spots of $0.5 \mathrm{~mm}$ diameter without the use of an aperture. However, it was not possible to produce larger beam spots with satisfactory energy density and beam homogeneity to allow annealing of the $2.5 \mathrm{~mm}$ cloverleaf patterns used for electrical measurements. Therefore, no electrical measurements were performed on the dye laser annealed samples. Energy densities for both lasers were adjusted by neutral density quartz attenuators and ranged from 0.05 to $0.9 \mathrm{~J} / \mathrm{cm}^{2}$. A small number of samples were furnace annealed at $850^{\circ} \mathrm{C}$ for $20 \mathrm{~min}$ in forming gas $(15 \%$ $\mathrm{H}_{2}, 85 \% \mathrm{~N}_{2}$ by volume) with the silicon nitride cap present and with the additional protection of two bulk GaAs wafers placed in contact with the samples.

\subsection{Optical tests}

Two optical experiments were performed: a transient reflectivity measurement during the process of laser annealing and Raman spectroscopy before and after the annealing. In the transient reflectivity experiment, the $514 \mathrm{~nm}$ line of an argon laser (Laser Ionics model 551A) was focused to a $50 \mu \mathrm{m}$ spot at the center of the focused spot from the excimer or dye laser. (No aperture was used in this case.) The signal was detected with a p-i-n photodiode behind a $514 \mathrm{~nm}$ spike interference filter to reject the scattered light from the pulsed laser. The signal was digitized and recorded with a transient digitizer (Tektronix model 7912AD) 
interfaced to an HP86 microcomputer. Both s and p polarizations were used. For the excimer system the probe beam was incident at an angle of $56^{\circ}$, which gives high sensitivity to changes in optical constants. For the dye laser system the probe was incident at $30^{\circ}$.

Three different types of GaAs samples were studied in transient reflectivity: a sample with an uncapped surface and samples with $\mathrm{Si}_{3} \mathrm{~N}_{4}$ caps of $63 \mathrm{~nm}$ and $79 \mathrm{~nm}$ thickness. The two types of capped samples had been implanted through the caps with $\mathrm{Si}$ $\left(6 \times 10^{12} \mathrm{~cm}^{-2}\right.$ at $\left.140 \mathrm{keV}\right)$ and Se $\left(2.2 \times 10^{12} \mathrm{~cm}^{-2}\right.$ at 320 $\mathrm{keV})$. For these low implant doses, our Raman scattering results show that the GaAs surface has only a very small amount of damage, which is not expected to affect significantly the optical or thermal properties of the $\mathrm{GaAs}$ or the $\mathrm{Si}_{3} \mathrm{~N}_{4}$.

Raman spectroscopy was performed in a reflection geometry using the $514.5 \mathrm{~nm}$ line of a Laser Ionics model 554A argon laser focused to a spot size of $<50 \mu \mathrm{m}$. A Spex model 1401 double spectrometer with photon counting electronics was used. Spectra could be obtained either before or after etching off the $\mathrm{Si}_{3} \mathrm{~N}_{4}$ cap since the transparent cap produced no observable features in the Raman spectra. Spectra were studied from several points in the annealed spots $(0.5$ to $2 \mathrm{~mm}$ in size) to determine the uniformity of recrystallization and carrier activation. To accomplish this spatially resolved probing, the sample was mounted on a stepper motor driven $\mathrm{X}-\mathrm{Y}$ translation stage controlled by a DEC 11/34 computer. Raman spectra of doped $<100>$ GaAs display two phonon-like peaks at $272 \mathrm{~cm}^{-1}$ and $295 \mathrm{~cm}^{-1}$, the $\mathrm{L}^{-}$and $\mathrm{LO}$ modes, and also a broad plasmon-like peak that at high densities is proportional to the square root of electron density: $\omega_{p}^{2} \cong n e^{2} / \varepsilon_{0} \kappa m^{*}$, where $n$ is the electron density, $e$ is the electron charge, $\varepsilon_{0}$ is the permittivity of free space, $\kappa$ is the dielectric constant, and $m^{*}$ is the effective mass of the electrons. The three Raman peaks are useful for determining both epitaxial regrowth and the density of free electrons in the annealed region.

\subsection{Electrical measurements and a multiple etching technique}

Van der Pauw measurements were performed on the cloverleaf shaped samples to determine the sheet resistance. Due to the brittle nature of $\mathrm{GaAs}$, it would be almost impossible to cleave such a pattern with small dimensions from the wafers. An alternative method, which we chose, is to pulse anneal the ion implanted wafer through a cloverleaf mask. The pattern was cut from a thin piece of sheet metal using a high-intensity laser beam. The laser used in this project was the Nd:YAG (Quanta Ray DCR 1A) infrared laser $(\lambda=1.06 \mu \mathrm{m})$. A code to generate the cloverleaf pattern was written for the HP86 computer. With the aid of an IEEE488 bus, the computer was interfaced to an $\mathrm{X}$-Y stage, and the sheet metal was then moved along the orientation of a cloverleaf pattern and cut sequentially by the laser.

After annealing, four small pieces of indium were placed in each of the ears of the sample and alloyed (sintered) at $380^{\circ} \mathrm{C}$ for $5 \mathrm{~min}$ in an ambient of $15 \% \mathrm{H}_{2}, 85 \% \mathrm{~N}_{2}$ by volume. Copper wire leads were soldered onto the indium contacts after the sample was mounted with wax to the Hall probe. A 4 in. electromagnet (Varian model V2300A) was utilized to produce a dc magnetic field of up to $0.7 \mathrm{~T}(7 \mathrm{kG})$ in the Hall effect experiment to determine the carrier sheet concentration and Hall mobility of the charge carriers. A Boonton gaussmeter (model 912) was used for field measurements and a current source (Lakeshore
Cryotronics model 110) provided a constant current that ranged typically from $1 \mu \mathrm{A}$ in lightly doped samples to $100 \mu \mathrm{A}$ in heavily doped samples. The measurements were performed away from any high-frequency equipment and in the dark.

To obtain a depth profile of the carrier distribution and carrier mobility variations produced by the ion implantation and annealing processes, the sample was repeatedly etched to remove one thin $(40 \mathrm{~nm})$ layer at a time. Here, the selective etchant was a mixture solution, $\mathrm{H}_{2} \mathrm{SO}_{4}-\mathrm{H}_{2} \mathrm{O}_{2}-\mathrm{H}_{2} \mathrm{O}$, which is the most commonly used etchant for $\mathrm{GaAs}$. It consists of $98 \mathrm{wt}$. \% (weight percent) solution of sulfuric acid, $30 \mathrm{wt}$. \% solution of hydrogen peroxide, and deionized water. ${ }^{13}$ The etching rate was obtained from a ternary diagram at $0^{\circ} \mathrm{C}$, as illustrated in Ref. 17. The selected etching rate was $0.5 \mu \mathrm{m} / \mathrm{min}$, since the activation layer of the sample was very thin, $\sim 0.2 \mu \mathrm{m}$. There are four etching surface states (A, B, C, D) on the diagram. Two of these regions correspond to a cloudy surface, and the other two result in a mirror-like surface. The composition of the solutions used for the etching process in this experiment was $\mathrm{H}_{2} \mathrm{SO}_{4}-\mathrm{H}_{2} \mathrm{O}_{2}-8 \mathrm{H}_{2} \mathrm{O}$ for low-dose $\mathrm{GaAs}$ and $17 \mathrm{H}_{2} \mathrm{SO}_{4}-3 \mathrm{H}_{2} \mathrm{O}_{2}-\mathrm{OH}_{2} \mathrm{O}$ for high-dose GaAs.

\subsection{Photoinduced current transient spectroscopy}

Since the initial description of the deep-level transient spectroscopy (DLTS) by Lang, ${ }^{18}$ much information about emission rates from deep-level traps in semiconductors has been obtained using various forms of transient capacitance analysis, generally known as DLTS. DLTS requires a depletion region in the semiconducting sample within which trap occupancies can temporarily be perturbed by an electrical ${ }^{19,20}$ or optical $^{21}$ (known as optically stimulated DLTS) pulse. Because of the depletion region, there is a need for a p-n junction or Schottky barrier contact. Since the region of interest is depleted, its recovery rate is limited by the emission from traps. The DLTS apparatus monitors this capacitance recovery transient and allows for the determination of the traps' signatures, such as activation energy, emission time constant, capture cross section, and density of traps.

Several experimental techniques have been developed to explore defects, impurities, and complexes in semiconductor materials. All of them utilize the property of deep energy levels for trapping of the carriers. Many of these techniques have been successfully applied to n- or p-type samples, but they lose their sensitivity when the resistivity of the material is very high or very low. Junction capacitance (or diffusion capacitance in the case of minority carrier injection pulses) can be used only for moderately doped samples. The problem in heavily doped $n^{+}$ or $\mathrm{p}^{+}$samples is that the breakdown voltage of a junction is very small due to significant tunneling of carriers through the potential barrier. Capacitance techniques cannot be used for semi-insulating samples either since the Debye length $L_{D}=$ $\left(\varepsilon \varepsilon_{o} k T / q^{2} n_{o}\right)^{1 / 2}$ is very large (on the order of a few millimeters for semi-insulating GaAs at room temperature) and typically exceeds sample dimensions. One technique that appears suitable for high-resistivity materials is often referred to as photoinduced transient spectroscopy ${ }^{22}$ or as optical transient current spectroscopy (OTCS). ${ }^{23}$ The current transient spectroscopy under the trap emission limited conditions was used to obtain trap parameters in the depletion regions of $\mathrm{GaP}: \mathrm{Cu}$ diodes, ${ }^{24}$ to study traps in $\mathrm{Si}$ p-n junctions, ${ }^{25,26}$ and to study traps at the $\mathrm{Si} / \mathrm{SiO}_{2}$ interface ${ }^{27}$ and at the channel-substrate interface in GaAs FETs. ${ }^{28}$ 
The photoinduced variation of this technique was applied to a variety of high-resistivity solids, such as CdS monocrystals, ${ }^{29}$ semi-insulating InP, ${ }^{30}$ and recently $\mathrm{CdS} / \mathrm{CdTe}$ thin-film solar cells. ${ }^{31}$

One problem encountered in our experiment with using the electrically stimulated DLTS was in the formation of Schottky contacts on the surface of pulse laser annealed GaAs. The Schottky contacts were very unreliable, had a very low breakdown voltage, or an ohmic contact was formed instead of a rectifying one. All of these problems would indicate a significant contribution of the tunneling mechanism of the conduction process in the metal-semiconductor contacts, which can occur when heavy doping (either from implants or from $\mathrm{Si}$ impurities introduced from the $\mathrm{SiN}$ cap) is used in the substrates. After many unsuccessful attempts this approach was abandoned in favor of the PITS. ${ }^{32}$ This technique allowed us to avoid several of the problems mentioned above and, in particular, the need of having a rectifying Schottky contact.

Photoinduced current transient spectroscopy involves using a light pulse to irradiate the sample surface. The optical pulse was obtained by using a $10 \mathrm{~mW} \mathrm{cw}$ He-Ne laser $(\lambda=632 \mathrm{~nm})$ along with a motordriven rotary light chopper. A $50 \%$ optical filter was used to cut down beam intensity to about $5 \mathrm{~mW}$. The light pulse duration was $1 \mathrm{~ms}$ with a pulse period of $30 \mathrm{~ms}$.

The samples used in the PITS experiment were identical with the samples utilized in the Hall measurements with four indium contacts, except that only two contacts along the square diagonal were used. The photocurrent was observed indirectly as a voltage drop across a calibrated resistor in series with the sample. A 6 $\mathrm{V}$ battery was used as a power supply. The signal was amplified by a low-noise preamplifier and processed by a boxcar integrator. The output signal was digitized, stored, and plotted by a system controlled by an HP86 computer. The details of this technique and analysis of the data will be published elsewhere.

\section{DISCUSSION OF RESULTS}

\subsection{Optical measurements}

The first step in our study was a transient reflectivity experiment to identify the GaAs melt threshold and the melt phase dynamics of the GaAs under the nitride cap. Second, we performed Raman spectroscopy measurements on a large number of anneal spots. This nondestructive measurement was used to identify the threshold energies for the GaAs implant layer recrystallization and for optimum carrier activation because the Raman spectra provide a reasonably good indication of the amount of carrier activation in the samples.

For pulsed dye laser excitation, the transient reflectivity at $514 \mathrm{~nm}$ is shown in Fig. 1. The observations were made with the probe beam incident at $30^{\circ}$. The data for $p$ polarization in Fig. 1(a) traces (1), (2), and (3), are for dye laser power densities of $0.10,0.14$, and $0.20 \mathrm{~J} / \mathrm{cm}^{2}$, respectively. The cap thickness was $59 \mathrm{~nm}$. In this case it is interesting to note that the signal drops as the solid GaAs rises in temperature but then rises abruptly when the molten phase occurs. (The molten phase is believed to be metallic.) In fact, a slight change in color of the cap can be seen by the eye at the laser irradiated spot. We believe this change may result from a change in composition of the $\mathrm{Si}_{3} \mathrm{~N}_{4}$ during the transient heating. This compositional change is undoubtedly occuring most rapidly during the molten phase and accounts for the rising slope during this period [see trace
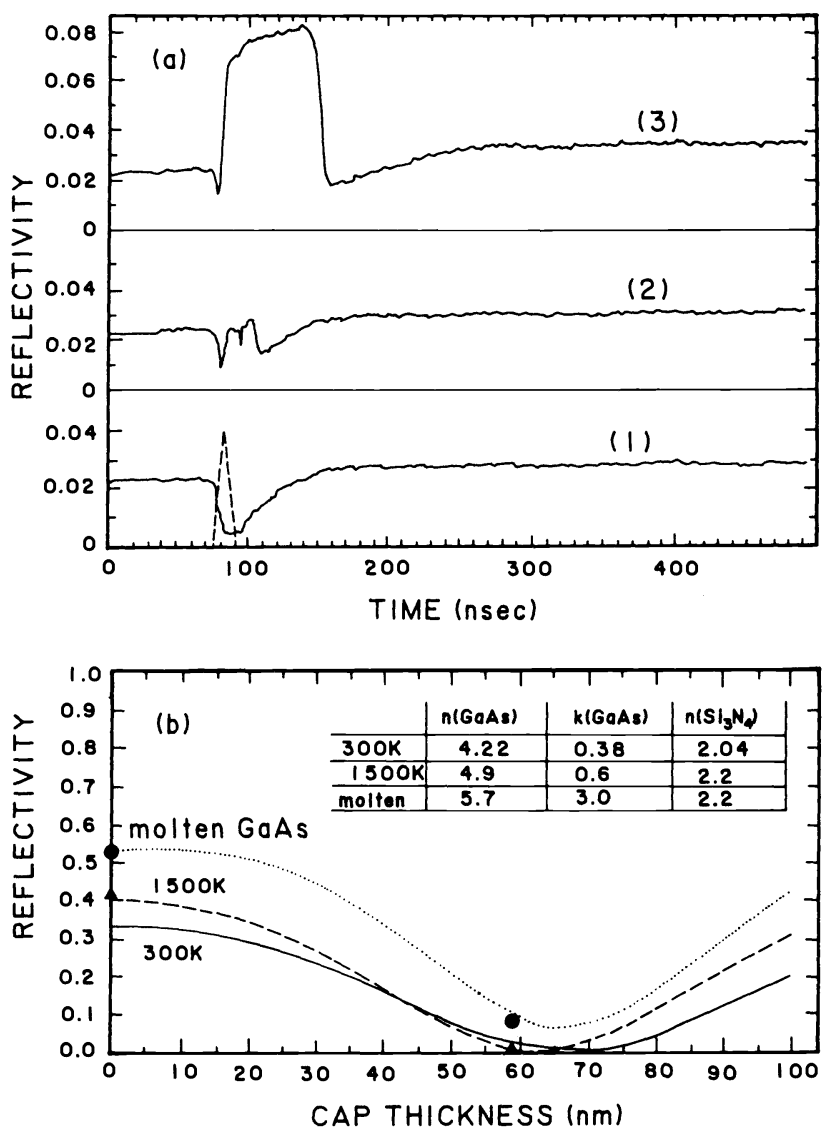

Fig. 1. (a) Reflectivity for $p$ polarization at $514 \mathrm{~nm}$ and angle of incidence of $30^{\circ}$ with dye laser pulse energies of (1) $0.10,(2) 0.14$, and (3) $0.20 \mathrm{~J} / \mathrm{cm}^{2}$. The cap thickness was $59 \mathrm{~nm}$. The dye laser pulse is the dashed curve in trace (1). (b) Calculated reflectivities at $30^{\circ}$ ( $\lambda$ $=514 \mathrm{~nm}$ ) vs cap thickness.

(3)]. On the other hand, inspection of the samples used in studies reported previously ${ }^{33}$ did not show this color change upon either dye laser or excimer laser irradiation and thus we believe that the initial composition of the silicon nitride was slightly different for the sample of Fig. 1. It is known that residual hydrogen can be present in the nitride film under some deposition conditions (e.g., excess $\mathrm{NH}_{3}$ or too low a substrate temperature during deposition). ${ }^{34}$ Such hydrogen would evolve rapidly as the temperature reaches the GaAs melting point in this experiment. We measured the dye laser annealed film ellipsometrically and found that the thickness was reduced by about $3.3 \mathrm{~nm}$, or about $5 \%$, or equivalently, the real part of the index of refraction was reduced by about $5 \%$ from 2.02 to 1.92 . Such a decrease has been observed as the substrate temperature is raised from $800^{\circ} \mathrm{C}$ to $1000^{\circ} \mathrm{C}$ during vapor deposition, ${ }^{34}$ and changes have also been observed as an annealing effect after deposition. ${ }^{35}$ The corresponding calculated reflectivity for this multilayer problem ${ }^{36}$ is presented in Fig. 1(b). The calculation shows clearly that for $59 \mathrm{~nm}$ cap thickness the reflectivity first falls and then rises as the melt phase is produced. This type of feature provides a sensitive test of the optical constants for $\mathrm{GaAs}$ and $\mathrm{Si}_{3} \mathrm{~N}_{4}$, as explained in detail elsewhere. ${ }^{16,36}$ Our principal interest here is in the duration of the GaAs melt phase.

The transient reflectivity during dye laser annealing [Fig. 1(a)] shows the usual indication of the GaAs melt phase duration but 
also the effect of the $\mathrm{Si}_{3} \mathrm{~N}_{4}$ cooldown. The effect of warming up of the cap and the changes in the cap's optical properties can be noticed in Fig. 1(a) trace (1), for which the pulse energy density is below the melt threshold. Melt phase initiation can be seen in trace (2) and the large increase in the reflectivity after the GaAs surface melted can be seen in trace (3). We have identified the threshold energies for GaAs melting beneath the cap to be approximately $0.1 \mathrm{~J} / \mathrm{cm}^{2}$ for both the $12 \mathrm{~ns}$ excimer pulses and the $8 \mathrm{~ns}$ dye laser pulses. This insensitivity to laser wavelength is explained below. For cap damage, the thresholds are 0.34 and $0.12 \mathrm{~J} / \mathrm{cm}^{2}$, respectively, for the excimer and dye lasers. At pulse energies above $\sim 0.3 \mathrm{~J} / \mathrm{cm}^{2}$, the cap lifts off and is usually blown away. In this case the transient reflectivity rapidly rises to values characteristic of the bare surface.

It can be concluded from reflectivity measurements that the effect of the cap on the melt threshold is not very large. A more significant difference is seen in the comparison between the UV and the deep red pulsed lasers. For the bare GaAs surface, the excimer laser pulse energy threshold for melting is only 0.05 $\mathrm{J} / \mathrm{cm}^{2}$, whereas the dye laser threshold is a factor of two higher at $0.10 \mathrm{~J} / \mathrm{cm}^{2}$. This difference is a consequence of the much shorter optical penetration depth $(\sim 13 \mathrm{~nm})$ of the excimer wavelength as compared to the dye laser $(\sim 70 \mathrm{~nm}){ }^{37}$

For the capped samples the threshold is essentially unchanged for the dye laser but rises for the excimer laser. This behavior is a consequence of the opposite effects of better optical coupling into the GaAs surface, especially for the dye laser, versus the additional heat sink presented by the capping layer. Thus, for a $60 \mathrm{~nm}$ cap and the $308 \mathrm{~nm}$ wavelength of the excimer laser, the reflectivity is reduced only slightly from 0.42 to 0.32 (the fraction of absorbed light energy in GaAs increases slightly), but the very short penetration in GaAs makes it sensitive to heat conduction into the $\mathrm{Si}_{3} \mathrm{~N}_{4}$ cap. Consequently, the threshold rises. For the dye laser, at $728 \mathrm{~nm}$, the reflectivity is reduced from 0.32 to 0.035 . This large change in reflectivity causes the amount of absorbed light energy to change from $68 \%$ without a cap to essentially $100 \%$ with the cap, but it does not cause the melt threshold to significantly decrease. The reason for this is that the deep penetration of the dye laser beam makes it less sensitive to the conduction of heat into the cap.

Raman spectroscopy was used to identify the threshold energies for the GaAs implant layer recrystallization and for optimum carrier activation. A comparison of Raman spectra from an implanted sample ( $\mathrm{Si}, 2 \times 10^{14} \mathrm{~cm}^{-2}$ ), laser annealed through the cap, with the spectra from the reference portion of the sample, which was laser annealed after etching off the cap, clearly shows that annealing through the cap gives much higher carrier activation. An increasing ratio of $\mathrm{L}^{-}$to $\mathrm{LO}$ lines in the Raman spectra indicates rising carrier activation since the LO peak arises only from the carrier depletion layer at the surface ${ }^{14}$ (Fig. 2). Notice that for dye laser annealing of capped $\mathrm{GaAs}$ [solid curve in Fig. 2(a)] a strong but narrow peak in activation occurs at $0.1 \mathrm{~J} / \mathrm{cm}^{2}$ and a second rise occurs near $0.34 \mathrm{~J} / \mathrm{cm}^{2}$. We believe this second rise in carrier concentration occurs because of the introduction of dopants (probably $\mathrm{Si}$ ) from the $\mathrm{Si}_{3} \mathrm{~N}_{4}$ cap during the pulsed laser anneal.

In the case of the $\mathrm{XeCl}$ excimer laser anneal [Fig. 2(b)], the dopant incorporation from the cap occurs again near $0.35 \mathrm{~J} / \mathrm{cm}^{2}$, where a rise in the $\mathrm{L}^{-} / \mathrm{LO}$ ratio is seen for the lightly implanted sample. A major difference from the dye laser annealing occurs for the uncapped samples, in which no carrier activation is seen

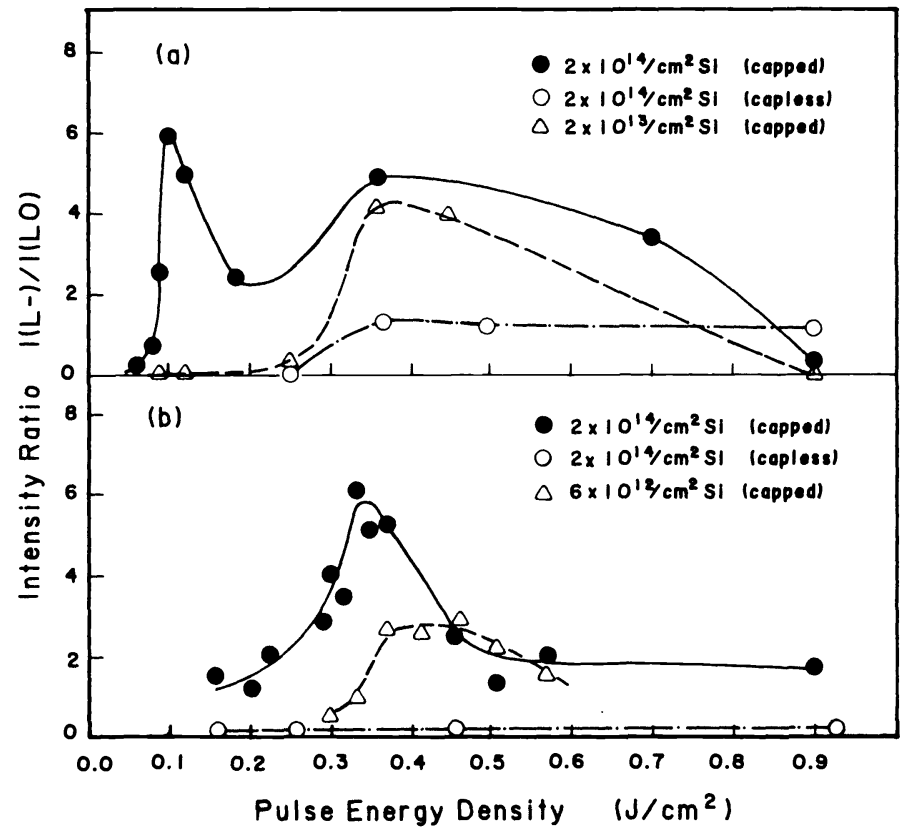

Fig. 2. Intensity ratio of the $L^{-}$to LO Raman modes from three samples observed with $514 \mathrm{~nm}$ excitation at room temperature: (a) annealed with $8 \mathrm{~ns}$ pulsed dye laser $(\lambda=728 \mathrm{~nm})$ and $(b)$ annealed with $12 \mathrm{~ns} \mathrm{XeCl} \mathrm{excimer} \mathrm{laser}(\lambda=308 \mathrm{~nm})$.

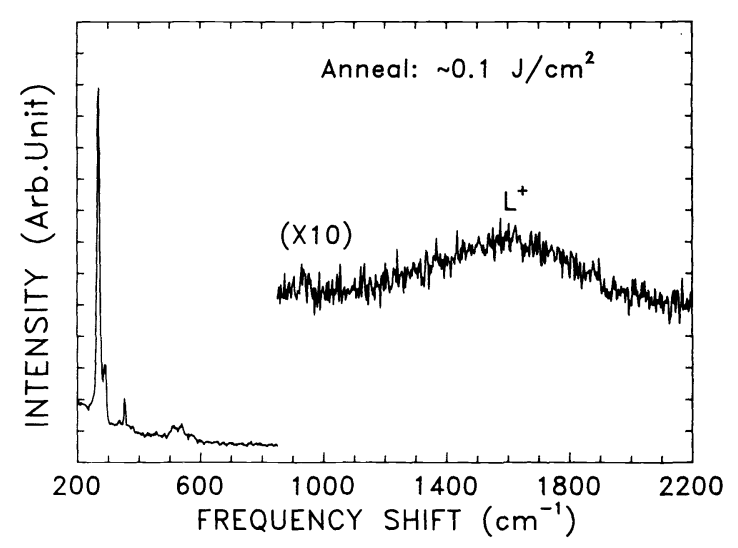

Fig. 3. Raman spectra of GaAs:Si $\left(2 \times 10^{14} / \mathrm{cm}^{2}\right)$ with $514.5 \mathrm{~nm} \mathrm{ex}$ citation obtained after annealing through a $59 \mathrm{~nm} \mathrm{Si} 3 \mathrm{~N}_{4}$ cap, using a 12 ns excimer laser pulse of energy density $0.34 \mathrm{~J} / \mathrm{cm}^{2}$.

for excimer annealing even for the $2 \times 10^{14} \mathrm{~cm}^{-2}$ sample. For the dye laser, significant doping from the cap appears at energy densities above $0.3 \mathrm{~J} / \mathrm{cm}^{2}$. The differences in annealing behavior between the two lasers, we believe, can be understood on the basis of the much different optical penetration depths. Further analysis of the Raman spectra are given in Ref. 14.

In addition, the plasmon $\left(\mathrm{L}^{+}\right)$peak in the Raman spectrum was used to calculate the carrier density directly (Fig. 3). The carrier concentration and carrier mobility were estimated from the position and width of the $\mathrm{L}^{+}$lines in the Raman spectra. It should be noted that the plasmon peak in the highest concentration sample lies near $1600 \mathrm{~cm}^{-1}$, which is almost $50 \%$ higher than the $\sim 1000 \mathrm{~cm}^{-1}$ observed for the heaviest Si doped MBE 
TABLE I. Hall effect measurements on excimer laser and furnace annealed samples.

\begin{tabular}{|c|c|c|c|c|}
\hline Sample Type & $\begin{array}{l}\text { Excimer laser } \\
\text { energy density } \\
\text { or furnace temp. }\end{array}$ & $\begin{array}{c}\text { Sheet carrier } \\
\text { concentration } \\
{\left[\mathrm{cm}^{-2}\right]}\end{array}$ & $\begin{array}{l}\text { Carrier } \\
\text { mobility } \\
\mathrm{cm}^{2} /\left(V_{s e c}\right)\end{array}$ & $\begin{array}{c}\text { Implanted } \\
\text { dose } \\
{\left[\mathrm{cm}^{-2}\right]}\end{array}$ \\
\hline $\begin{array}{l}\text { Se doped GaAs } \\
320 \mathrm{keV} \\
\mathrm{Si}_{3} \mathrm{~N}_{4} \text { cap: } 79 \mathrm{~nm}\end{array}$ & $\begin{array}{l}0.27 \\
0.3 \\
0.33\end{array}$ & $\begin{array}{l}2.60 \times 12 \\
2.03 \times 13 \\
1.48 \times 13\end{array}$ & $\begin{array}{r}116.65 \\
41.47 \\
69.07\end{array}$ & $2.2 \times 10^{12}$ \\
\hline Si doped GaAs & 0.32 & $8.89 \times 12$ & 25.63 & \\
\hline 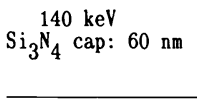 & $\begin{array}{l}0.29 \\
0.24 \\
0.23 \\
\end{array}$ & $\begin{array}{l}7.84 \times 12 \\
6.75 \times 12 \\
1.02 \times 12 \\
\end{array}$ & $\begin{array}{r}92.6 \\
5.1 \\
56.1 \\
\end{array}$ & $6 \times 10^{13}$ \\
\hline $\begin{array}{l}\mathrm{Si} \text { doped GaAs } \\
320 \mathrm{keV} \\
\mathrm{Si}_{3} \mathrm{~N}_{4} \mathrm{cap}: 60 \mathrm{~nm}\end{array}$ & $\begin{array}{l}0.265 \\
0.24\end{array}$ & $\begin{array}{l}7.4 \times 13 \\
3.64 \times 13\end{array}$ & $\begin{array}{l}273.22 \\
234.01\end{array}$ & $2 \times 10^{14}$ \\
\hline $\begin{array}{l}\text { Se doped GaAs } \\
320 \mathrm{keV} \\
\mathrm{Si}_{3} \mathrm{~N}_{4} \text { cap: } 79 \mathrm{~nm}\end{array}$ & $\begin{array}{l}\mathrm{T}=850^{\circ} \mathrm{C} \\
\mathrm{t}=20 \mathrm{~min}\end{array}$ & $\begin{array}{l}1.10 \times 10^{12} \\
1.18 \times 10^{12}\end{array}$ & $\begin{array}{l}3200 \\
3152\end{array}$ & $2.2 \times 10^{12}$ \\
\hline
\end{tabular}

samples thus far reported, which were identified* as having carrier concentrations of about $1.3 \times 10^{19} \mathrm{~cm}^{-3}$. These results compare well with data obtained by using direct electrical measurements on the samples.

\subsection{Hall measurements}

The Hall effect technique is widely used in determining the electrical characteristics of active semiconductor substrates. It is by far the most effective method of quantifying the degree of free carrier activation as well as the carrier type. There are two common methods in measuring sheet resistance, the four-point probe technique $^{38}$ and the Van der Pauw method. ${ }^{39}$ The fourpoint probe, despite being the most common method to use for measuring the resistivity of semiconductor wafers, is unsuitable for our pulsed laser annealed samples. One of the reasons for this is that the distances between the probes $(6 \mathrm{~mm})$ exceed the $3 \mathrm{~mm}$ region of the annealed diameter. Since the four-point probe requires all four test points to be in close contact with the annealed sample, this method was rejected in favor of the Van der Pauw technique. The Van der Pauw technique has the advantage of being applicable to flat semiconductor samples of arbitrary shape.

Three ion implanted doses were considered for the electrical measurements. The ion doses, types of impurities, cap thicknesses, and implantation energies are listed in Table I. Only the samples annealed with the excimer laser had anneal spots large enough to be tested electrically (see Sec. 2.1 above).

These samples were annealed over a narrow energy range from 0.23 to $0.33 \mathrm{~J} / \mathrm{cm}^{2}$, which the Raman scattering indicated might be optimum for the highest carrier activation. The results are compared with similar samples that were furnace annealed at $850^{\circ} \mathrm{C}$ for $20 \mathrm{~min}$ in a forming gas $\left(15 \% \mathrm{H}_{2}, 85 \% \mathrm{~N}_{2}\right.$ by volume) with the $\mathrm{Si}_{3} \mathrm{~N}_{4}$ cap present. The results of Hall measurements (Table I) indicate that the furnace annealing is quite effective in activation of low-dose samples, and a high electron mobility results. A summary of all data from the measurements and the overall derived results for electron mobility, carrier activation, and free sheet carrier concentration are shown in Table I.

*J. Tsang, private communication (1987).
It has been reported by Nojima ${ }^{8}$ that the effects of pulsed laser annealing on low-dose GaAs:Si $\left(<<1 \times 10^{14} \mathrm{~cm}^{-2}\right)$ show little to no carrier activation when a $Q$ switched pulsed ruby laser was used. Our results on capped samples, however, indicate the contrary. For the GaAs:Se sample at $2.2 \times 10^{12} \mathrm{~cm}^{-2}$, we found that the free carrier concentration exceeded the ion implanted dose (see Table I). Thus, it is our conclusion that these dopants could only have originated from the $\mathrm{Si}_{3} \mathrm{~N}_{4}$ cap itself. Using the Van der Pauw technique, we found a low electron mobility for the sample, indicating the existence of residual damage. This, we believe, may be attributed to the additional impurities that were driven in from the cap and/or to residual defects from the ion implanted layer. It has also been suggested ${ }^{8}$ that pulsed laser annealing may introduce some defects due to the fast quenching rate of the molten layer of GaAs.

From these observations, the following conclusions can be drawn: first, that the apparently high carrier activation for lowdose ion implanted $\mathrm{GaAs}$ is caused by doping from the cap during PLA; second, that the effect of the encapsulants is twofold. Although it reduces outdiffusion of arsenic from the substrate surface, it may introduce additional n-type dopants from the $\mathrm{Si}$ ions from the cap during the process of laser annealing. Too much laser power causes damage, which may lower the mobility. This can clearly be seen from the decreasing trend in electron mobility as the laser power intensity is increased from 0.27 to $0.33 \mathrm{~J} / \mathrm{cm}^{2}$ (see Table I).

The more heavily implanted Si samples $\left(6 \times 10^{13}\right.$ and $2 \times 10^{14}$ $\mathrm{cm}^{-2}$ ), despite being laser annealed through an encapsulant, did not show any indication of additional doping at low pulse energy densities (see Table I). Although the free sheet concentration measured below their implanted doses, one cannot completely rule out the possibility of some impurity doping from the encapsulant. From Table I one will notice a similar trend in all three samples, where the sheet carrier concentration steadily increases with laser intensity until it peaks at an optimum point between 0.265 and $0.32 \mathrm{~J} / \mathrm{cm}^{2}$. In both cases, the measured electron mobilities were low.

\subsection{Depth profiling of carriers by a multiple etching technique}

The depth profile here refers to the carrier concentration and the mobility variation as a function of the depth. Since Van der Pauw and Hall measurements provide sheet resistance $R_{S}$ and sheet Hall coefficient $H_{S}$, one can determine effective mobility $\mu_{\text {eff }}$ from

$\mu_{\mathrm{eff}}=\frac{H_{s}}{R_{s}}$

and the number of carriers $/ \mathrm{cm}^{2}$ (known as the sheet concentration) from

$N_{s}=\left(R_{s} q \mu_{\mathrm{eff}}\right)^{-1}$

where $q$ is a magnitude of electronic charge.

Both $\mu_{\text {eff }}$ and $N_{s}$ are weighted averages since the carrier concentration and carrier mobility are depth dependent in an implanted layer. Thus, the Hall coefficient $H$ must be expressed as a summation of the average values of carrier concentration $n_{i}$ and mobility $\mu_{i}$ in $i$ layers of thickness $d_{i}$ : 
$H=\frac{\sum_{i} n_{i} \mu_{i}^{2} d_{i}}{q\left(\sum_{i} n_{i} \mu_{i} d_{i}\right)^{2}}$.

By making the assumption that the Hall mobility is equal to the conductivity mobility, the conductivity $\sigma$ is expressed by

$\sigma=\frac{q}{d} \sum_{i} n_{i} \mu_{i} d_{i}$

since $\mu_{i}=1 /\left(q N_{S} R_{S}\right)$ in each layer. Then

$R_{S}=(\sigma d)^{-1}=\frac{1}{q \sum_{i} n_{i} \mu_{i} d_{i}}$,

where $d=\sum d_{i}$.

From Eqs. (1) and (3), one can observe that the effective Hall coefficient and sheet resistivity are related to the carrier concentration and mobility in each layer. Equivalently, each layer carrier concentration and mobility certainly can be expressed by two different Hall coefficients and sheet resistivities obtained before and after each active layer is removed.

Mayer ${ }^{40}$ reported one method to determine $\mu_{i}$ and $n_{i}$ from the combination of stripping techniques and Hall measurements. Following Mayer, carrier concentration $n_{i}$ by volume in the $i$ th layer and the $i$ th layer mobility $\mu_{i}$ can be found from

$\frac{\left(H_{S}\right)_{i}}{\left(R_{S}\right)_{i}^{2}}-\frac{\left(H_{S}\right)_{i+1}}{\left(R_{S}\right)_{i+1}^{2}}=q n_{i} \mu_{i}^{2} d_{i}$,

$\left(R_{S}\right)_{i}^{-1}-\left(R_{S}\right)_{i+1}^{-1}=q n_{i} \mu_{i} d_{i}$

then

$\mu_{i}=\frac{\Delta\left(H_{S} / R_{S}^{2}\right)_{i}}{\Delta\left(1 / R_{S}\right)_{i}}$

$n_{i}=\frac{\Delta\left(1 / R_{S}\right)_{i}}{q d_{i} \mu_{i}}$

Since samples studied in the course of the depth profiling experiment were ion implanted with $320 \mathrm{keV}$ and a dose $\Phi=$ $2.2 \times 10^{12} \mathrm{~cm}^{-2}$ during processing, a standard carrier distribution called the LSS profile ${ }^{41}$ can be obtained from calculations of the projected range $\left(R_{p}\right)$ and standard deviation $\left(\Delta R_{p}\right)$. Thus,

$N(x)=\frac{\Phi}{\sqrt{2 \pi} \Delta R_{p}} \exp \left[-\frac{1}{2}\left(\frac{x-R_{p}}{\Delta R_{p}}\right)^{2}\right]$.

Figure 4 shows the furnace annealed Se-GaAs carrier distribution as determined by the electrical measurements and a comparison with its LSS profile. The projected range of the carriers (1200 $\AA)$ is about the same as a peak in the measured density of electrons. The second observation is that a deep tail appears in the carrier distribution after annealing. This is due to thermal diffusion of implanted impurities during the 20 min long, hightemperature annealing process, which causes redistribution of impurities. Figure 5 shows a mobility distribution. One can find

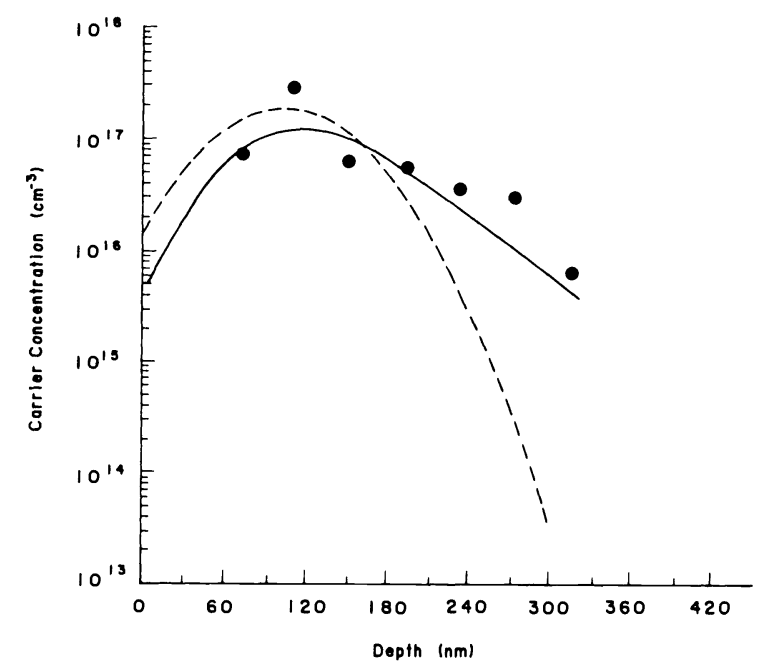

Fig. 4. Carrier concentration profile for furnace annealed Se-GaAs sample $\left(2.2 \times 10^{12} \mathrm{~cm}^{-2}\right)$.

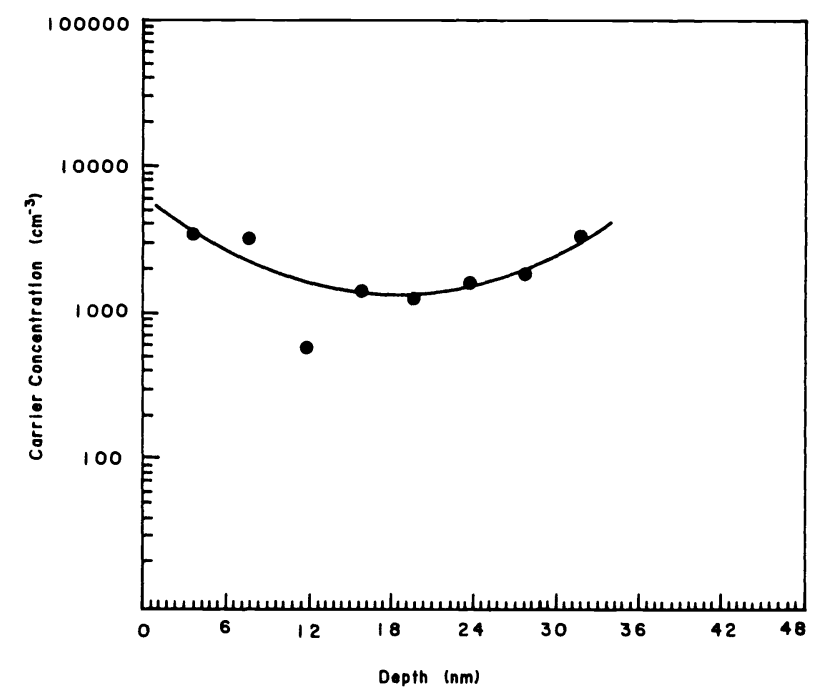

Fig. 5. Carrier mobility profile for furnace annealed Se-GaAs sample $\left(2.2 \times 10^{12} \mathrm{~cm}^{-2}\right)$.

that the mobility is high both near the surface and far away from the surface. It is lowest at the point of $1200 \AA$. This is due to the impurity scattering of electrons, which causes mobility to be inversely proportional to the carrier concentration.

Only the low-dose $\left(2.2 \times 10^{12} \mathrm{~cm}^{-3}\right)$ Se doped GaAs samples pulsed laser annealed with a few different light intensities were characterized in the depth profiling experiment. Other samples have not been used to this point to study the carrier concentration profiles because of the destructive nature of this experiment and the limited number of samples available for optical and electrical characterization.

Contrary to the poor activation of low-dose PLA samples, ${ }^{8}$ our results indicate carrier concentrations have exceeded $100 \%$ of implanted densities in the SiN capped low-dose samples. However, the active layers are very shallow $(\sim 40 \mathrm{~nm})$, as indicated by the depth profiling on PLA samples (see Fig. 6). The samples become very highly resistive after a few etching steps, which is an indication that the semi-insulating substrate has been 


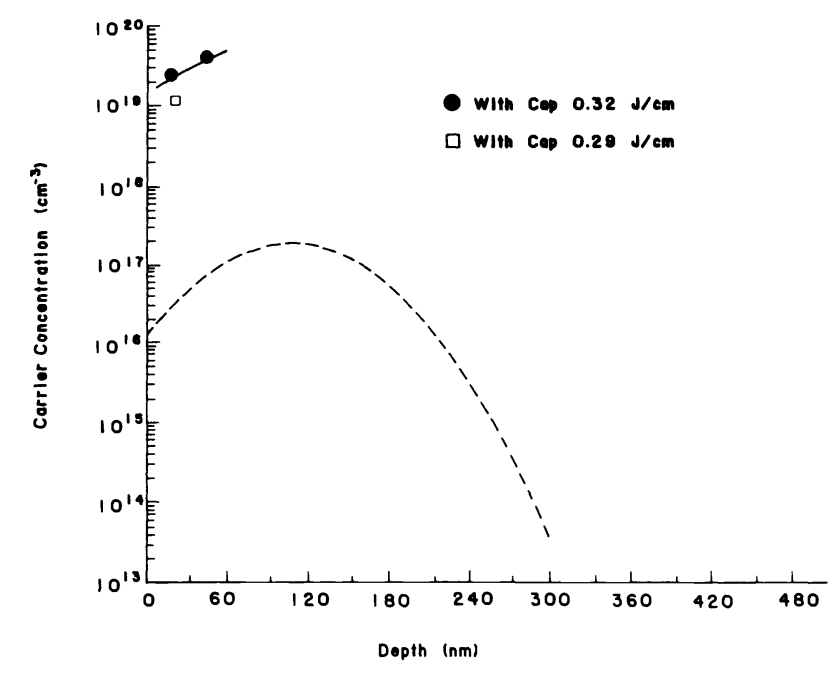

Fig. 6. Pulsed laser annealed Se-GaAs carrier distribution $\left(2.2 \times 10^{12}\right.$ $\mathrm{cm}^{-2}$ ).

reached. Nojima ${ }^{8}$ reported that the sample ( $\mathrm{Si}$ ion implanted GaAs with $1 \times 10^{15} \mathrm{~cm}^{-2}$ ) annealed by a pulsed ruby laser at $0.79 \mathrm{~J} / \mathrm{cm}^{2}$ without a nitride cap had an average mobility of 450 $\mathrm{cm}^{2} \mathrm{~V}^{-1} \mathrm{~s}^{-1}$, and the carrier concentration was high $\left(\sim 3 \times 10^{18}\right.$ $\mathrm{cm}^{-3}$ ) in the vicinity of the surface. Our profiling experiment performed on Se doped GaAs $\left(2.2 \times 10^{12} \mathrm{~cm}^{-2}\right)$ for excimer laser light intensity of $0.30 \mathrm{~J} / \mathrm{cm}^{2}$ indicated that the electron concentration exceeded $1 \times 10^{19} \mathrm{~cm}^{-3}$ near the surface $(\sim 40$ $\mathrm{nm})$. The high donor density and a significant surface scattering due to the very shallow active layer resulted in a low mobility of about $250 \mathrm{~cm}^{2} \mathrm{~V}^{-1} \mathrm{~s}^{-1}$.

As was discussed earlier, pulsed laser annealing introduces some amount of impurities into samples from the silicon nitride cap, which causes the sheet concentration to exceed the implanted fluence of donors in the low-dose samples. It is very likely that impurities are also introduced from the $\mathrm{Si}_{3} \mathrm{~N}_{4}$ cap into the highly doped samples, but the amount is small compared with implanted impurity dose.

\subsection{Results of PITS experiment}

The representative photoinduced transient spectroscopy spectra for lightly doped $\left(4 \times 10^{12} \mathrm{~cm}^{-2}\right)$ and heavily doped $\left(6 \times 10^{14}\right.$ $\mathrm{cm}^{-2}$ ) samples are shown in Figs. 7(a) and 7(b), respectively. The corresponding Arrhenius plots are shown in Figs. 8(a) and 8(b), respectively.

The labels $\mathrm{P}_{1}$ through $\mathrm{P}_{5}$ correspond to the peaks observed on PITS spectra for all of the samples. There are three distinct peaks $P_{1}, P_{2}$, and $P_{3}$ present in lightly doped laser annealed samples and three peaks $P_{1}, P_{2}$, and $P_{4}$ in furnace annealed samples. They correspond to defects with the activation energy of $\sim 0.05,0.1,0.3$, and $0.56 \mathrm{eV}$. The spectra for highly doped samples $\left(1 \times 10^{14}\right.$ and $\left.6 \times 10^{14} \mathrm{~cm}^{-2}\right)$ both furnace and laser annealed indicate the presence of an additional peak $P_{5}$ above room temperature. Due to the weak signal and broad shape of this peak, it is difficult to resolve it accurately. The deep level corresponding to this peak is at approximately $0.80 \mathrm{eV}$ with a capture cross section of about $10^{-11} \mathrm{~cm}^{2}$. This defect level may have been introduced by heavy implantation damage (also reported by Yuba et al. ${ }^{42}$ or it may be related to the EL2 defect
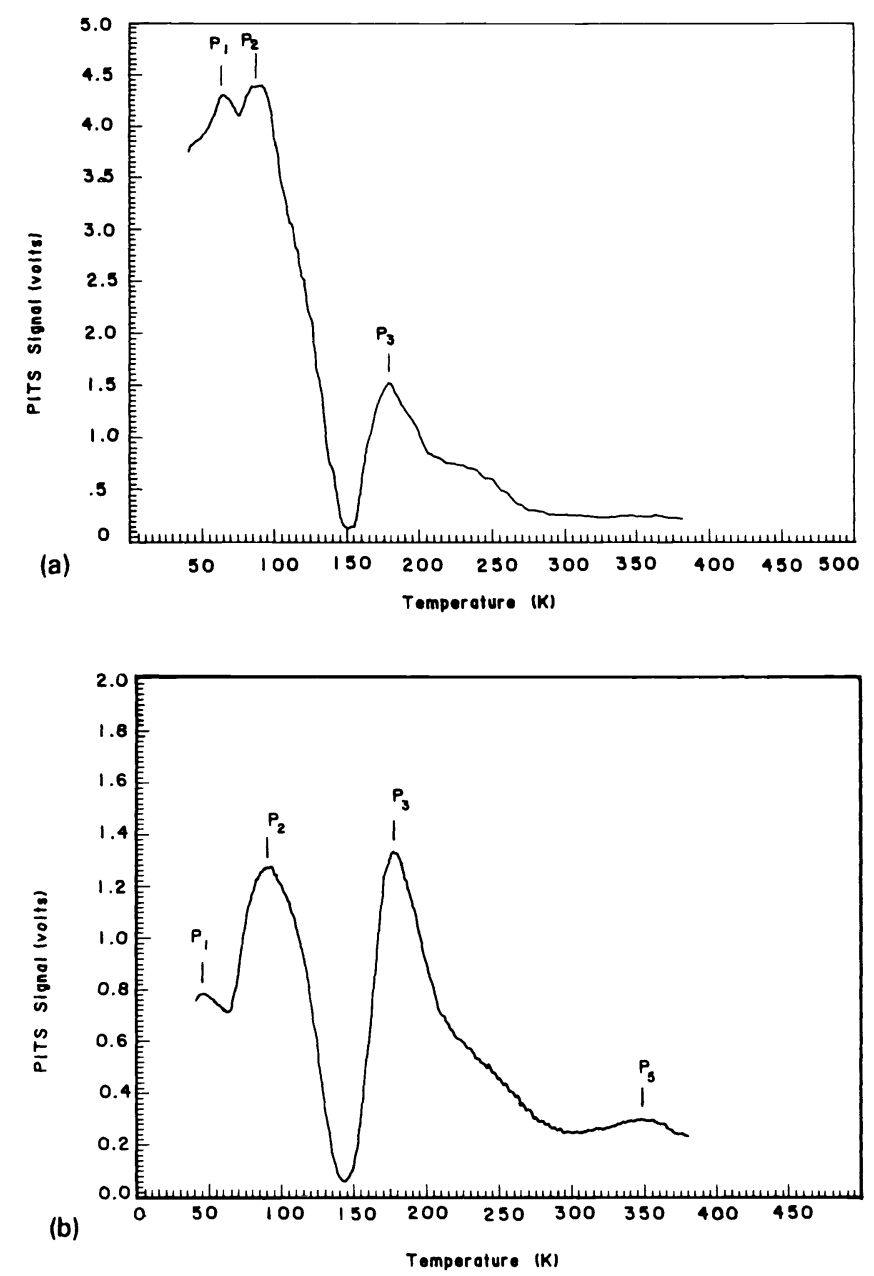

Fig. 7. (a) PITS spectra on low-dose PLA Si-GaAs at $t_{1}=0.3 \mathrm{~ms}$ and $t_{2}=2.4 \mathrm{~ms}$ at dose $=4 \times 10^{12} \mathrm{~cm}^{-2}$ and dose $=2 \times 10^{13} \mathrm{~cm}^{-2}$. (b) PITS spectra on high-dose PLA Si-GaAs at $t_{1}=0.3 \mathrm{~ms}$ and $t_{2}=2.4$ $\mathrm{ms}$ at dose $1 \times 10^{14} \mathrm{~cm}^{-2}$ and dose $=6 \times 10^{14} \mathrm{~cm}^{-2}$.

observed in GaAs substrates grown by the LEC (liquid encapsulated Czochralski) method without chromium compensation. The EL2 level is generally observed at a temperature of about $390 \mathrm{~K}$.

The next major peak in the pulsed laser annealed samples, $P_{3}$, with an activation energy of $0.3 \mathrm{eV}$, appears in the temperature range 170 to $180 \mathrm{~K}$. This defect can be identified with a level known as EL6 in the literature. ${ }^{32,43}$

The last two peaks, $P_{2}$ and $P_{1}$, appear at very low temperature and correspond to deep-level defects with a small activation energy $\left(E_{t}<0.1 \mathrm{eV}\right)$. Similar defects with activation energies of about 60 to $80 \mathrm{meV}$ have been reported previously in LPE (liquid phase epitaxy) layers ${ }^{44}$ and in bulk $\mathrm{GaAs},{ }^{45}$ but their origin is unknown.

\section{SUMMARY}

A study of carrier activation and mobility was performed in pulsed laser annealed samples of $\mathrm{GaAs}$ implanted with doses of $\mathrm{Si}$ and Se from $2.2 \times 10^{12}$ to $6.0 \times 10^{14} \mathrm{~cm}^{-2}$. The samples were annealed using a pulsed $\mathrm{XeCl}$ excimer laser $(\lambda=308 \mathrm{~nm})$ with a pulse duration of $12 \mathrm{~ns}$ and a pulsed dye laser $(\lambda=728 \mathrm{~nm})$ 


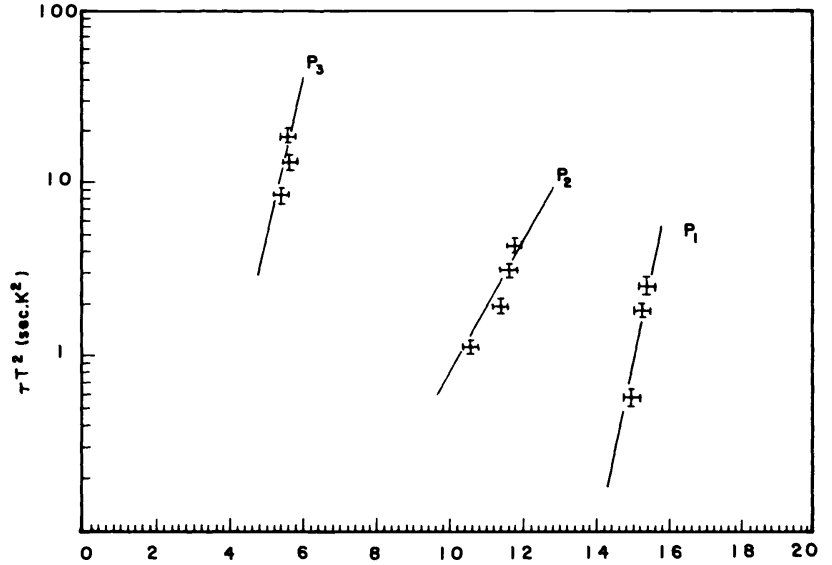

(a)

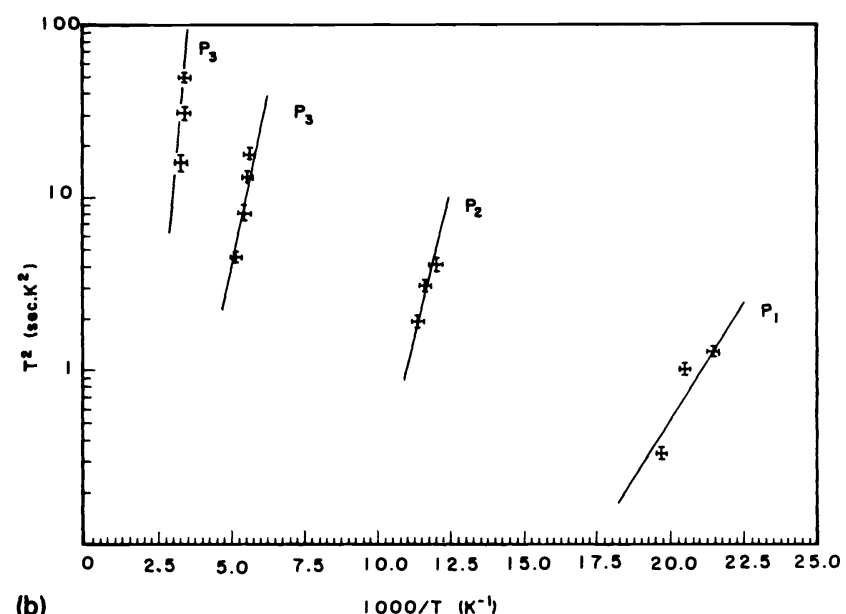

Fig. 8. (a) Arrhenius plot of a PLA $\left(0.32 \mathrm{~J} / \mathrm{cm}^{2}\right)$ Si-GaAs $\left(2.0 \times 10^{13}\right.$ $\mathrm{cm}^{-2}$ ) sample. (b) Arrhenius plot of a PLA $\left(0.32 \mathrm{~J} / \mathrm{cm}^{2}\right)$ Si-GaAs $(1.0 \times$ $10^{14} \mathrm{~cm}^{-2}$ ) sample.

with an $8 \mathrm{~ns}$ pulse. Very high carrier concentrations of $3 \times 10^{19}$ and $1.5 \times 10^{19} \mathrm{~cm}^{-3}$, as deduced from the $\mathrm{L}^{+}$peak of the Raman spectrum, were obtained for the best n-type GaAs samples annealed with the dye laser and the excimer laser, respectively. The dye laser consistently produced higher activation than excimer laser annealing.

The Hall effect results show that pulsed laser annealing can effectively produce electrical activity of implanted impurities for both low-dose as well as very heavy dose implanted GaAs. However, for low-dose $\mathrm{Se}$ implanted $\mathrm{GaAs}$, most or perhaps all of the doping comes from the $\mathrm{Si}_{3} \mathrm{~N}_{4}$ encapsulant. For the higher dose samples that were Si implanted, an $\sim 37 \%$ recovery of the implanted dose was found. Hence, a dose dependency is observed, coinciding with results of earlier experiments. ${ }^{2}$

We found that despite some success in carrier activation, the overall electron mobilities for all tested samples gave low readings $\left(<300 \mathrm{~cm}^{2} \mathrm{~V}^{-1} \mathrm{~s}^{-1}\right)$. We do not know at this point the cause for such low mobilities. However, we have a strong indication that the problem may be attributed to the excess dopants introduced from the encapsulants during annealing and large surface scattering in a shallow active layer in PLA samples. Some indication of the defect structure was obtained from photoinduced current transient spectroscopy. Five major peaks were observed on the PITS spectra in the temperature range from 60 to $400 \mathrm{~K}$, corresponding to traps with activation energies between 0.06 to $0.80 \mathrm{eV}$. The details of this experiment will be reported later.

Finally, we found the optimum excimer laser intensity for annealing of $\sim 60 \mathrm{~nm}$ thick $\mathrm{Si}_{3} \mathrm{~N}_{4}$ capped $\mathrm{GaAs}$ to range from 0.26 to $0.33 \mathrm{~J} / \mathrm{cm}^{2}\left(0.17 \mathrm{~J} / \mathrm{cm}^{2}\right.$ seems to be an optimum for the dye laser for similar samples). The transient reflectivity experiment identified the threshold energies for cap damage as 0.34 and $0.12 \mathrm{~J} / \mathrm{cm}^{2}$ for excimer and dye lasers, respectively. These results were supported by Raman scattering on these samples. For the high-dose Si implanted samples, Raman scattering indicates n-type carrier concentrations well above $1 \times 10^{19} \mathrm{~cm}^{3}$. However, these results have not yet been confirmed with Hall measurements reported here because of difficulties in sample preparation.

Our studies show that PLA can produce doping from a capping layer by the laser melting process without the need for an ion implantation step. However, it appears that significant numbers of defects are introduced by these $\mathrm{Si}_{3} \mathrm{~N}_{4}$ caps. Other capping layers might yield better results.

\section{ACKNOWLEDGMENTS}

This work was supported in part by National Science Foundation grant No. ECS-8505161 and by NSF equipment grant No. CHE8310646. The Se doped ion implanted GaAs samples were donated by Ian Burrows of Honeywell GaAs IC Product Center, Richardson, Texas, and the $\mathrm{Si}$ doped GaAs samples were donated by Wright Patterson Air Force Base, Dayton, Ohio, and by C. E. Wu from Motorola Semiconductor Research and Development Laboratories, Phoenix, Arizona. Their help is gratefully acknowledged.

\section{REFERENCES}

1. D. H. Lowndes, in Pulsed Laser Processing of Semiconductors, R. F. Wood, C. W. White, and R. T. Young, eds., Semiconductors and Semimetals Vol. 23, p. 471, Academic, New York (1984).

2. See, for example, the papers by J. D. Sansbury and J. F. Gibbons, Rad. Effects. 6, 269 (1970), and R. G. Hunsperger and O. J. Marsh, Rad. Effects. 6, 263 (1970).

3. See papers by C. P. Lee, R. Zucca, and B. M. Welch, "Orientation effect on planar GaAs Schottky barrier field effect transistors,' Appl. Phys. Lett. 37, 311 (1980), and T. Nakamura et al., "Raman spectra from heat-treated semi-insulating GaAs," Appl. Phys. Lett. 38, 13 (1981).

4. P. M. Asbeck et al., "Effects of $\mathrm{Cr}$ redistribution on electrical characteristics of ion-implanted semi-insulating GaAs,"' IEEE Electron Device Lett. EDL-1(3), 35 (1980)

5. H. Nishi et al., "AlN encapsulant for fabrication of implanted GaAs ICs," Inst. Phys. Conf. Ser. No. 63, 365 (1981)

6. D. H. Lowndes, J. W. Cleland, W. H. Christie, and R. E. Eby, "Pulsed ruby laser annealing of $\mathrm{Zn}, \mathrm{Mg}$, Se, and $\mathrm{Si}$ ion implants in semiconducting GaAs," Mat. Res. Soc. Symp. Proc. 1, 223 (1981).

7. A. H. Oraby et al., "Pulse laser annealing effects in Si-implanted GaAs," Jpn. J. Appl. Phys. 23, 326 (1984).

8. S. Nojima, "Laser annealing effects in ion-implanted GaAs," J. Appl. Phys. 53, 5028-5036 (1982); S. Nojima, "Defects in GaAs induced by laser annealing,' J. Appl. Phys. 52, 7445 (1981).

9. S. G., Liu et al., J. Electrochem. Soc. 127, 925 (1980).

10. C. L. Anderson, "Material-process interactions in the annealing of gallium arsenide," in Laser and Electron-Beam Interactions with Solids, B. R. Appleton and G. K. Cellar, eds., pp. 653-665, Elsevier, Amsterdam (1982)

11. F. H. Eisen, "Laser and electron beam annealing of GaAs," in Laser and Electron-Beam Processing of Materials, C. W. White and P. S. Peercy, eds., p. 309, Academic, New York (1980).

12. P. A. Pianetta, C. A. Stolte, and J. L. Hansen, "Pulsed e-beam and ruby laser annealing of ion-implanted GaAs," in Laser and Electron-Beam Processing of Materials,' C. W. White and P. S. Peercy, eds., p. 328, Academic, New York (1980).

13. S. S. Kular, B. J. Sealy, et al., "Laser annealing of capped and uncapped GaAs," Electron. Lett. 15, 413 (1979). 
14. A. Compaan, S. C. Abbi, H. D. Yao, A. Bhat, and D. W. Langer, "Excimer and dye laser annealing of silicon-nitride-capped, Si-implanted GaAs,", J. Appl. Phys. 62, 2561 (1987).

15. D. E. Aspnes and A. A. Studna, Phys. Rev. B:27, 985 (1983)

16. A. Bhat, H. D. Yao, A. Compaan, A. Horak, and A. Rys, "Pulsed laser heating of silicon nitride capped GaAs: optical properties at high temperature," J. Appl. Phys. 64(5), 2591 (1988).

17. S. Iida and $\mathrm{K}$. Ito, "Selective etching of gallium arsenide crystals in $\mathrm{H}_{2} \mathrm{SO}_{4}$ $\mathrm{H}_{2} \mathrm{O}_{2}-\mathrm{H}_{2} \mathrm{O}$ system," J. Electrochem. Soc.: Solid State Science 118(5), 768-771 (1971).

18. D. V. Lang, "Deep-level transient spectroscopy: a new method to characterize traps in semiconductors," J. Appl. Phys. 45(7), 3023 (1974).

19. G. V. Miller, D. V. Lang, and L. C. Kimmerling, Ann. Rev. Mater. Sci. 7, 377 (1977).

20. E. Meijer, L. A. Ledebo, and Z. Wang, Solid State Commun. 46, 255 (1983).

21. A. Mittoneau, G. M. Martin, and A. Mircea, Inst. Phys. Conf. Ser. 33a, 73 (1977).

22. G. M. Martin and D. Bois, Electrochem. Soc. Ext. Abstr. 78-3, 32 (1978).

23. C. H. Hurtes, M. Boulou, A. Mittoneau, and D. Bois, Appl. Phys. Lett. $32,821(1978)$

24. B. W. Wessels, J. Appl. Phys. 47, 1131 (1976).

25. J. A. Borsuk and R. M. Swanson, J. Appl. Phys. 52, 6704 (1981).

26. S. D. Brotherton, J. Appl. Phys. 55, 3535 (1984).

27. M. C. Chen and D. V. Lang, Phys. Res. Lett. 51, 427 (1983).

28. W. B. Leigh, J. S. Blakemore, and R. Y. Koyama, IEEE Trans. Electron. Dev. ED-32, 1835 (1985).

29. O. Yoshie and M. Kaminara, Jpn. J. Appl. Phys. 22, 621 and 629 (1983).

30. J. K. Rhee and P. K. Bhattacharya, J. Appl. Phys. 53, 4247 (1982).

31. L. C. Isett, J. Appl. Phys. 56, 3508 (1984).

32. R. E. Kremer, M. C. Ankan, J. C. Abele, and J. S. Blakemore, "Transient photoconductivity measurements in semi-insulating GaAs. I: Analog approach,"'J. Appl. Phys. 62(6), 2424 (1987).

33. A. Rys et al., "Very heavily doped n-type GaAs obtained with pulsed laser annealing," in Advanced Processing of Semiconductor Devices II, H. G. Craighead and J. Narayan, eds., Proc. SPIE 945, 41-48 (1988).

34. K. E. Bean, P. S. Gleim, R. L. Yeakley and W. R. Runyan, J. Electrochem. Soc.: Solid State Science 114, 733 (1967); H. R. Phillip, in Handbook of Optical Constants of Solids, E. D. Palik, ed., p. 771, Academic, New York (1985).

35. R. Szweda, Physica Scripta 129B, 435 (1982).

36. A. Bhat, A. Horak, H. D. Yao, S. C. Abbi, A. Rys, and A. Compaan, "Effects of silicon nitride caps on excimer and dye laser annealing of GaAs,"' Bull. Am. Phys. Soc. 32, 653 (1987)

37. M. L. Theye and A. Gheorghiu, Solar Energy Mater. 8, 331 (1982).

38. F. M. Smits, "Measurement of sheet resistivities with the four-point probe," Bell Syst. Tech. J. 37, 711 (1958)

39. L. J. Van der Pauw, "A method of measuring the resistivity and Hall coefficient on lamellae of arbitrary shape," Phillips Tech. Rev. (Jan. 1958).

40. J. W. Mayer, O. J. Marsh, G. A. Shifrin, and R. Baron, "Ion implantation of silicon. II: Electrical evaluation using Hall-effect measurements," Canadian J. Phys. 45, 4073 (1967).

41. J. Linhard, M. Scharff, and H. E. Schiott, "Range concepts and heavy ion ranges," Mat. Fys. Medd. Dan. Vidensk. Selsk. 33, 1 (1963).

42. Y. Yuba et al., "Deep levels in implanted and laser annealed GaAs studied by current and capacitance-transient measurements,' Inst. Phys. Conf. Ser. 63, Chap. 5 (1981)

43. G. M. Martin et al., "Electron traps in bulk and epitaxial GaAs crystals," Electron. Lett. 13, 666 (1977).

44. S. J. Pearton et al., "Deep trapping centers in n-GaAs surface barrier diodes for nuclear radiation detection,' Electron. Lett. 16, $12(1980)$

45. G. N. Maracas, "DLTS analysis of GaAs MESFETS and effects of deep levels of devices performance," doctoral dissertation, Cornell Univ. (1982).

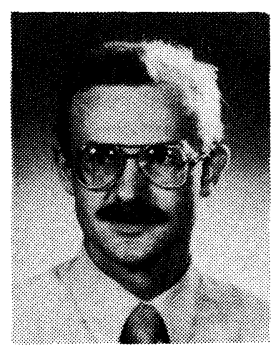

Andrzej Rys received his integrated BS/MS degree in electronics engineering from the Technical University of Wroclaw, Poland, in 1978 and the Ph.D. degree in electical engineering from Texas Tech University in 1983. From 1977 to 1979 he worked on the technology and reliability of silicon FET transistors at the Institute of Electron Technology in Wroclaw. His Ph.D. dissertation concerned the design and fabrication of III-V heterojunction devices and the investigation of deep energy levels in GaAs and AIGaAs, using fast transient capacitance techniques. He joined the faculty in the Department of Electrical and Computer Engineering at Kansas State University in 1983. In the summer of 1984 he was employed by Motorola Semiconductor Research and Development Laboratories in Phoenix, where he studied the deep impurity levels and their influence on electrical parameters of microwave MESFETs. His current research interests are mainly concerned with pulsed laser annealing of ion implanted III-V alloy semiconductors, spectroscopy of defects in semiconductors, device modeling, and VLSI circuit design. Dr. Rys is a member of the IEEE Electron Devices Society, Eta Kappa Nu, Sigma Xi, and SPIE.

Yanan Shieh: Biography and photograph not available.

Alvin D. Compaan received his Ph.D. degree in physics from the University of Chicago in 1971, spent two years as a research associate at New York University, and then joined the faculty of the Department of Physics at Kansas State University, where this research was performed. In July of 1987 he moved to the University of Toledo, where he is currently a professor of physics and director of the Eitel Institute for Silicate Science. His research program has focused on laser spectroscopy for semiconductor characterization (Raman scattering and photoluminescence) as well as the use of pulsed lasers for semiconductor surface modification (ion implantation and laser annealing) and thin film growth by pulsed laser ablation deposition. His current research emphasizes III-V and II-VI compound semiconductor materials.

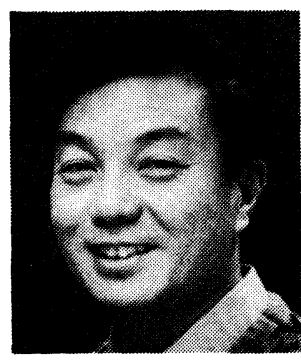

Huade Yao obtained his undergraduate education in physics from Shanghai Normal University. He received his MS degree in 1986 and Ph.D. degree in 1989, both in physics, from Kansas State University. He is now a research associate in the Department of Electrical Engineering of the University of Nebraska. His research interests include optical properties of semiconductors by Raman scattering and photoluminescence, pulsed laser modification of solid state surfaces, and in situ ellipsometry measurements. Dr. Yao is a member of Sigma Xi, Sigma Pi Sigma, APS, and MRS

Ajit Bhat: Biography and photograph not available. 